Mini Review: Open Access

\title{
Growth-Differentiation Factor-15 at Risk Stratification in Diabetes Patients: Usefulness, Discrepancies, and Hype
}

\author{
Alexander E. Berezin* \\ Internal Medicine Department, State Medical University, Ukraine
}

${ }^{*}$ Corresponding author: Alexander E. Berezin, Professor, MD, PhD, Consultant of Cardiology Unit, Internal Medicine Department, State Medical University, 26, Zaporozhye, Ukraine, Postcode 69035, Tel: +380612894585 , E-mail:dr_berezin@mail.ru

\begin{abstract}
Growth differentiation factor-15 (GDF-15) is a stress-responsive cytokine, which belongs to super family of the transforming growth factor beta. GDF-15 is widely presented in the various cells (macrophages, vascular smooth muscle cells, adipocytes, cardiomyocytes, endothelial cells, fibroblasts), tissues (adipose tissue, vessels, tissues of central and peripheral nervous system) and organs (heart, brain, liver, placenta) and it plays an important role in the regulation of the inflammatory response, growth and cell differentiation. Elevated GDF-15 was found in patients with established cardiovascular (CV) diseases including hypertension, stable coronary artery disease, acute coronary syndrome, myocardial infarction, ischemic and none ischemicinduced cardiomyopathies, heart failure, atrial fibrillation, as well as stroke, type two diabetes mellitus (T2DM), chronic kidney disease, infection, liver cirrhosis, malignancy. Therefore, aging, smoking, and various environmental factors, i.e. chemical pollutants are other risk factors that might increase serum GDF-15 level. Although GDF-15 has been reported to be involved in energy homoeostasis and weight loss, to have anti-inflammatory properties, and to predict CV diseases and CV events in general or established CV disease population, there is no large of body of evidence regarding predictive role of elevated GDF-15 in T2DM subjects. The mini review is clarified the role of Growth-Differentiation Factor-15 in T2DM subjects.
\end{abstract}

\section{Keywords}

Cardiovascular diseases, Cardiovascular risk, Diabetes mellitus, Biomarkers, Growth-Differentiation Factor-15, Inflammation, Prediction

\section{Abbreviations}

AKT: serine/threonine kinase, ATF3: pro-survival protein activating transcription factor 3, eNO: endothelial nitric oxide, eNOS: endothelial nitric oxide synthase, $\mathrm{PI} 3 \mathrm{~K}$ : phosphoinositide 3-kinase, NF-kB: nuclear factor kappa-B

\section{Introduction}

Cardiovascular (CV) diseases remain to be leading cause of mortality and morbidity worldwide [1]. Recent clinical studies have shown that the majority of $\mathrm{CV}$ deaths occurred in patients who had not experience a non-fatal CV or renal event whiled who had diabetes or diabetes-associated settings, i.e. obesity, insulin resistance, peripheral artery disease [2,3]. The significant impact of diabetes on $\mathrm{CV}$ events and outcomes relate to interplay of preexisting traditional CV risk factors with negative effect of glucose metabolism, lipotoxicity, adipose tissue dysfunction, excessive oxidative stress [4]. All these factors are able to induce an endothelial dysfunction, lead to cardiac remodeling and hypertrophy that contribute in vascular dysintegrity and cardiac dysfunction [5].

Although there is a large body of evidence that diabetes increases substantially the risk of death, CV events and heart failure, a deeper understanding of the complex pathogenic mechanisms of the $\mathrm{CV}$ remodeling in diabetes is required. In fact, the traditional CV risk factors do not completely predict the presence of subclinical injury of heart and vessels in diabetic population [6,7]. In this context, the early stage of target-organ damage in diabetes might be determined by biological markers that reflect different faces in pathogenesis of the disease. Because an inflammation plays an important role in manifestation and nature evolution of diabetes and diabetesrelated $\mathrm{CV}$ complications, inflammatory biomarkers became to use in the diagnostic assessment of diabetics suspected of CV diseases [8]. Therefore, predictive role of peak concentration of various inflammatory biomarkers in diabetics is suggested $[9,10]$.

The most commonly used inflammatory biomarker in established diabetes is highly selective C-reactive protein (hs-CRP), which correlates well with $\mathrm{CV}$ complications, poorer metabolic control and severe hypoglycaemia, although low sensitivity and specificity of this biomarker was found [11-14]. Apart from serial testing of hs-CRP, which is time-consuming, other novel pro-inflammatory biomarkers like Growth-Differentiation Factor-15 (GDF-15) have been proposed risk stratify patients with diabetes including type two diabetes mellitus (T2DM) [15]. The aim of the mini review is clarified the role of GDF15 in prediction of CV outcomes and target-organ damages in T2DM.

\section{Biological Role and Function of Growth Differentiation Factor-15}

GDF-15 (recently known as macrophage inhibitory cytokine-1) is a member of the transforming growth factor beta (TGF- $\beta$ ) super family [16]. It is widely presented in the various cells (macrophages, vascular smooth muscle cells, adipocytes, cardiomyocytes, endothelial cells, fibroblasts), tissues (adipose tissue, vessels, tissues of central and 


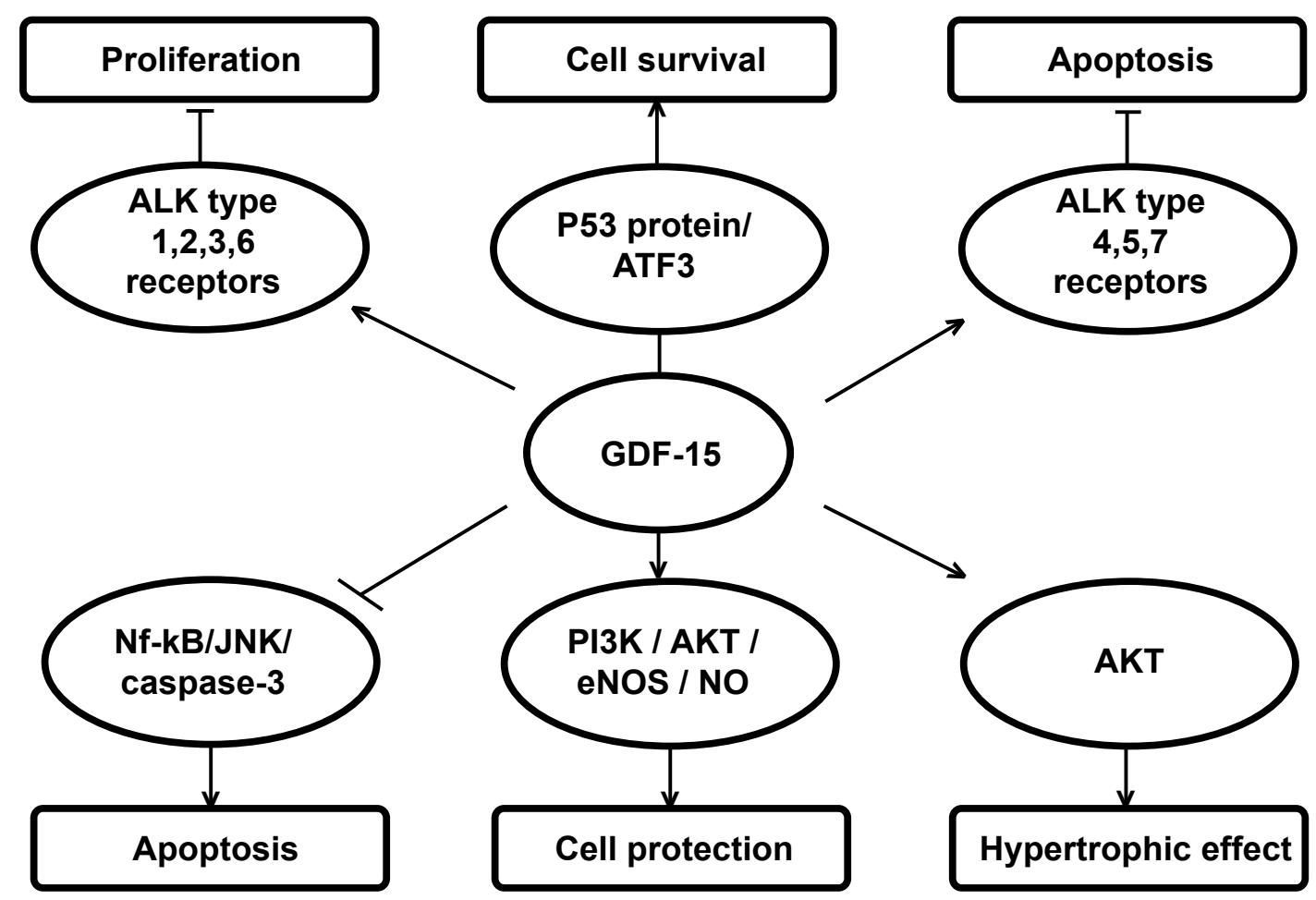

Figure 1: Molecular targets and controversial effects of GDF-15. Figure shows that GDF-15 is able to act the regulation of the inflammatory response, growth and cell differentiation through several ways that are linked with the progression and prognosis of the CV diseases.

peripheral nervous system) and organs (heart, brain, liver, placenta). GDF-15 has been shown to play an important role in the regulation of the inflammatory response, growth and cell differentiation [17].

The main sources of GDF-15 releasing in diabetes are macrophages, white adipose tissue and liver cells. However, the over expression of GDF-15 on surfaces of cardiomyocites in diabetics unless CV diseases including heart failure was not found. Probably, patients with established ischemic-induced CV disease might have extended source for GDF-15 releasing. The triggers of production of GDF-15 are biomechanical stress, ischemia, anoxia and inflammatory cytokines (tumor necrosis factor alpha, interleukins (IL)-2, IL-4, IL6), angiotensin II, macrophage colony stimulating factor, and TGF- $\beta$.

The direct molecular biological target of GDF-15 is p53 protein, which is induced by oxidative stress and has anti-apoptotic effects on target cells. This effect closely associates with the pro-survival protein activating transcription factor 3 (ATF3), which is negatively regulated by p53 protein expression. Therefore, GDF15 inhibits c-Jun N-terminal kinase, Bcl-2-associated death promoter, and epidermal growth factor receptor, as well as activates various intracellular signaling pathways, i.e. Smad, endothelial nitric oxide (eNO) synthase, phosphoinositide 3-kinase, and serine/threonine kinase. The final result of this interrelation is suppression of both tumor necrosis factor alpha and IL-6 synthesis, protect of pressureinduced cardiac hypertrophy, improvement of vascular integrity, and increasing cardiomyocyte and endothelial cell viability [18].

Several animal studies were determined the positive effect of over-expressed GDF-15 on cell viability independently related to encoding a novel microRNA 3189 that functions as a potent ATF3 mediated regulator of cell death [19]. Inversely, GDF15 probably is able to bind with matrix metalloproteinase 26 that facilitate the proapoptotic effect of this cytokine [20]. Moreover, hyperglycemia in diabetic patients increases reactive oxygen species that may activate nuclear factor $\mathrm{kB} /$ Janus kinases / caspase-3 pathway, suppresses eNO synthase and induces cellular injury and cell death [21]. Adipocytokines in obese individuals may promote p53 activation in adipose tissue and leads to insulin resistance and T2DM. Whether pro-apoptotic ability of GDF-15 depends on type of tissues is still not understood. Overall, GDF15 may act as protective, anti-apoptotic and sometimes pro-apoptotic factor with metabolic capacities contributed growth tissue, maturation and differentiation of various cells (Figure 1).

\section{Diagnostic and Predictive Value of Elevated Serum Growth Differentiation Factor-15}

GDF-15 is discussed a putative stress-responsive antiinflammatory cytokine that increased in patients with established CV diseases, stroke, T2DM, chronic kidney disease, infection, liver cirrhosis, malignancy, respiratory and kidney failure, ineffective erythropoiesis in several anemias [22-32]. Age, smoking, and environmental factors (chemical pollutants) are other risk factors that might increase serum GDF-15 level. Interestingly, that GDF-15 was able to be an independent marker of $\mathrm{CV}$ dysfunction and $\mathrm{CV}$ disease in the elderly [33].

Among T2DM population serum level of GDF-15 was positively associated with body mass index, body fat, fasting glucose level, glycated hemoglobin, insulin resistance index, waist to height ratio, age, arterial blood pressure, triglycerides, creatinine, glucose, hs-CRP [34], diabetic nephropathy [35,36] and inversely with insulin, anemia [34,35]. Therefore, Dominguez-Rodriguez et al. [37] reported that elevated GFD-15 might predict diabetic cardiomyopathy.

In fact, GDF-15 was found a predictive biomarker in CV mortality in general population and among subjects with asymptomatic atherosclerosis [38]. Elevated GDF-15 predicted survival in patients with idiopathic pulmonary arterial hypertension [39], heart failure [40], myocardial infarction [41], stable CAD [42], after cardiac resynchronization therapy [43], and patients with aortic stenosis [44]. Moreover, GDF-15 associated well with CV recurrent events after acute coronary syndrome independently of clinical predictors, B-type natriuretic peptide, and high-sensitivity C-reactive protein [45,46]. Velders et al. [46] reported that NT-proBNP and GDF-15 measured on admission in patients with ST elevated myocardial infarction treated with primary percutaneous coronary intervention might provide incremental risk stratification. According opinion of investigators, both biomarkers are the most valuable due to the association with both $\mathrm{CV}$ disease and spontaneous myocardial infarction [46]. Wallentin et al. [47] have reported that GDF-15 was 
able to improve prognostication of both CV and cancer mortality / morbidity beyond established risk factors and biomarkers of cardiac, renal dysfunction and inflammation. Therefore, GDF-15 was found a risk factor for major bleeding, mortality, and stroke in atrial fibrillation [48].

Accumulating evidences have shown that GDF15 could associate with the development and prognosis of T2DM. Although GDF-15 has been reported to be involved in energy homoeostasis and weight loss, to have anti-inflammatory properties, and to predict CV diseases and $\mathrm{CV}$ events in general or established CV disease population, there is no large of body of evidence regarding predictive role of elevated GDF-15 in T2DM subjects. Surprisingly, in individuals before T2DM manifestation the concentration of GDF-15 was not independently associated with incident T2DM in follow up period [49]. Inversely, elevated GDF-15 has demonstrated a predictive value for $\mathrm{CV}$ complications, all cause mortality and $\mathrm{CV}$ mortality in diabetic individuals with established CV diseases, nephropathy, hypertension, rheumatic diseases [37,50-52]. Overall these findings indicate that clinically significance of similar associations between circulating levels of anti-inflammatory cytokines. i.e. GDF-15, incident T2DM, and all cause mortality and CV mortality strongly requires a confirmation preferably in prospective epidemiological studies. Whether GDF-15 is an important prognostic marker in diabetics without existing $\mathrm{CV}$ disease is still not clear and this question might be addressed to future studies.

In conclusion, the role of elevated GDF-15 as prognostic marker in diabetics is widely discussed. GDF-15 was found a predictor of subsequent insulin resistance and impaired glucose control in obese subjects. The prediction of elevated GDF-15 in T2DM individuals without $\mathrm{CV}$ diseases or other co-morbidities that might increase the $\mathrm{CV}$ risk is under recognized. The future perspectives regarding utility of GDF-15 in routine clinical practice probably affects their ability to predict $\mathrm{CV}$ outcomes and mortality, while novel validated models for risk stratification of T2DM patients with pre existed CV diseases are needed.

\section{References}

1. Mozaffarian D, Benjamin EJ, Go AS, Arnett DK, Blaha MJ, et al. (2015) Heart disease and stroke statistics-2015 update: a report from the American Heart Association. Circulation 131: e29-322.

2. Jhund PS, McMurray JJ, Chaturvedi N, Brunel P, Desai AS, et al. (2015) Mortality following a cardiovascular or renal event in patients with type 2 diabetes in the Altitude trial. Eur Heart J.

3. Rayner JJ, Neubauer S, Rider OJ (2015) The paradox of obesity cardiomyopathy and the potential for weight loss as a therapy. Obes Rev 16: $679-690$

4. Stinkens R, Goossens GH, Jocken JW, Blaak EE (2015) Targeting fatty acid metabolism to improve glucose metabolism. Obes Rev 16: 715-757.

5. Beatty AL, Ku IA, Bibbins-Domingo K, Christenson RH, DeFilippi CR, et al. (2015) Traditional Risk Factors Versus Biomarkers for Prediction of Secondary Events in Patients With Stable Coronary Heart Disease: From the Heart and Soul Study. J Am Heart Assoc 4.

6. Barrios C, Pascual J, Otero S, Soler MJ, Rodríguez E, et al. (2015) Diabetic nephropathy is an independent factor associated to severe subclinical atheromatous disease. Atherosclerosis 242: 37-44

7. Cavender MA, Steg PG, Smith SC, Eagle K, Ohman EM, et al. (2015) Impact of Diabetes on Hospitalization for Heart Failure, Cardiovascular Events, and Death: Outcomes at 4 Years from the REACH Registry. Circulation.

8. Grossmann V, Schmitt VH, Zeller T, Panova-Noeva M, Schulz A, et al (2015) Profile of the Immune and Inflammatory Response in Individuals With Prediabetes and Type 2 Diabetes. Diabetes Care 38: 1356-1364.

9. Klüppelholz B, Thorand B, Koenig W, de Las Heras Gala T, Meisinger C, et al (2015) Association of subclinical inflammation with deterioration of glycaemia before the diagnosis of type 2 diabetes: the KORA S4/F4 study. Diabetologia.

10. Esser N, Paquot N, Scheen AJ (2015) Inflammatory markers and cardiometabolic diseases. Acta Clin Belg 70: 193-199.

11. Weber KS, Nowotny B, Strassburger K, Pacini G, Müssig K, et al (2015) The Role of Markers of Low-Grade Inflammation for the Early Time Course of Glycemic Control, Glucose Disappearance Rate, and ß-Cell Function in Recently Diagnosed Type 1 and Type 2 Diabetes. Diabetes Care 38: 17581767.
12. Effoe VS, Correa A, Chen H, Lacy ME, Bertoni AG (2015) High-Sensitivity C-Reactive Protein Is Associated With Incident Type 2 Diabetes Among African Americans: The Jackson Heart Study. Diabetes Care 38: 1694-1700.

13. Seven E, Husemoen LL, Sehested TS, Ibsen H, Wachtell K, et al. (2015) Adipocytokines, C-reactive protein, and cardiovascular disease: a populationbased prospective study. PLoS One 10: e0128987.

14. Ridker PM, MacFadyen J, Libby P, Glynn RJ (2010) Relation of baseline high-sensitivity C-reactive protein level to cardiovascular outcomes with rosuvastatin in the Justification for Use of statins in Prevention: an Intervention Trial Evaluating Rosuvastatin (JUPITER). Am J Cardiol 106: 204-209.

15. El-Refaei MF, Abduljawad SH, Alghamdi AH (2014) Alternative Medicine in Diabetes - Role of Angiogenesis, Oxidative Stress, and Chronic Inflammation. Rev Diabet Stud 11: 231-244.

16. Unsicker K, Spittau B, Krieglstein K (2013) The multiple facets of the TGF- $ß$ family cytokine growth/differentiation factor-15/macrophage inhibitory cytokine-1. Cytokine Growth Factor Rev 24: 373-384.

17. Fairlie WD, Moore AG, Bauskin AR, Russell PK, Zhang HP, et al. (1999) MIC-1 is a novel TGF-beta superfamily cytokine associated with macrophage activation. J Leukoc Biol 65: 2-5.

18. Adela R, Banerjee SK (2015) GDF-15 as a Target and Biomarker for Diabetes and Cardiovascular Diseases: A Translational Prospective. J Diabetes Res 2015: 490842

19. Jones MF, Ling Li X, Subramanian M, Shabalina SA, Hara T, et al. (2015) Growth differentiation factor-15 encodes a novel microRNA 3189 that functions as a potent regulator of cell death. Cell Death Differ 22: 1641-1653.

20. Li S, Wang Y, Cao B, Wu Y, Ji L, et al. (2014) Maturation of growth differentiation factor 15 in human placental trophoblast cells depends on the interaction with Matrix Metalloproteinase-26. J Clin Endocrinol Metab 99: E2277-2287.

21. Zhang Y, Liang X, Liao S, Wang W, Wang J, et al. (2015) Potent Paracrine Effects of human induced Pluripotent Stem Cell-derived Mesenchymal Stem Cells Attenuate Doxorubicin-induced Cardiomyopathy. Sci Rep 5: 11235

22. Kukaszyk E, Kukaszyk M, Koc-Zorawska E, Tobolczyk J, Bodzenta-Kukaszyk A et al. (2015) Iron Status and Inflammation in Early Stages of Chronic Kidney Disease. Kidney Blood Press Res 40: 366-373.

23. Zhu ZD, Sun T (2015) Association between growth differentiation factor-15 and chronic heart failure in coronary atherosclerosis patients. Genet Mol Res 14: 2225-2233.

24. Meluzín J, Tomandl J (2015) Can biomarkers help to diagnose early heart failure with preserved ejection fraction? Dis Markers 2015: 426045.

25. Mueller T, Leitner I, Egger M, Haltmayer M, Dieplinger B (2015) Association of the biomarkers soluble ST2, galectin-3 and growth-differentiation factor-15 with heart failure and other non-cardiac diseases. Clin Chim Acta 445: 155-160.

26. Velders MA, Wallentin L, Becker RC, van Boven AJ, Himmelmann A, et al. (2015) Biomarkers for risk stratification of patients with ST-elevation myocardial infarction treated with primary percutaneous coronary intervention: Insights from the Platelet Inhibition and Patient Outcomes trial. Am Heart $\mathrm{J}$ 169: 879-889.

27. Griner SE, Joshi JP, Nahta R (2013) Growth differentiation factor 15 stimulates rapamycin-sensitive ovarian cancer cell growth and invasion. Biochem Pharmacol 85: 46-58.

28. Hanatani S, Izumiya Y, Takashio S, Kojima S, Yamamuro M, et al. (2014) Growth differentiation factor 15 can distinguish between hypertrophic cardiomyopathy and hypertensive hearts. Heart Vessels. 29: 231-237.

29. O'Meara E, de Denus S, Rouleau JL, Desai A (2013) Circulating biomarkers in patients with heart failure and preserved ejection fraction. Curr Heart Fail Rep 10: 350-358

30. Rhodes CJ, Wharton J, Wilkins MR (2013) Pulmonary hypertension: biomarkers. Handb Exp Pharmacol 218: 77-103.

31. Montoro-García S, Hernández-Romero D, Jover E, García-Honrubia A, Vilchez JA, et al. (2012) Growth differentiation factor-15, a novel biomarker related with disease severity in patients with hypertrophic cardiomyopathy. Eur J Intern Med 23: 169-174.

32. Guenancia C, Kahli A, Laurent G, Hachet O, Malapert G, et al. (2015) Preoperative growth differentiation factor 15 as a novel biomarker of acute kidney injury after cardiac bypass surgery. Int J Cardiol 197: 66-71.

33. Lind L, Wallentin L, Kempf T, Tapken H, Quint A, et al. (2009) Growthdifferentiation factor-15 is an independent marker of cardiovascular dysfunction and disease in the elderly: results from the prospective investigation of the vasculature in uppsala seniors (PIVUS) study. Eur Heart J 30: 2346-2353.

34. Kempf T, Guba-Quint A, Torgerson J, Magnone MC, Haefliger C, et al. (2012) Growth differentiation factor 15 predicts future insulin resistance and impaired glucose control in obese nondiabetic individuals: results from the XENDOS trial. Eur J Endocrinol 167: 671-678. 
35. Hong JH, Choi YK, Min BK, Park KS, Seong K, et al. (2015) Relationship between hepcidin and GDF15 in anemic patients with type 2 diabetes without overt renal impairment. Diabetes Res Clin Pract 109: 64-70.

36. Chrysovergis K, Wang X, Kosak J, Lee SH, Kim JS, et al. (2014) NAG-1/ GDF-15 prevents obesity by increasing thermogenesis, lipolysis and oxidative metabolism. Int J Obes (Lond) 38: 1555-1564.

37. Dominguez-Rodriguez A, Abreu-Gonzalez P, Avanzas P (2014) Usefulness of growth differentiation factor-15 levels to predict diabetic cardiomyopathy in asymptomatic patients with type 2 diabetes mellitus. Am J Cardiol 114 890-894.

38. Rohatgi A, Patel P, Das SR, Ayers CR, Khera A, et al. (2012) Association of growth differentiation factor-15 with coronary atherosclerosis and mortality in a young, multiethnic population: observations from the Dallas Heart Study. Clin Chem 58: 172-182.

39. Rhodes CJ, Wharton J, Howard LS, Gibbs JS, Wilkins MR (2011) Red cell distribution width outperforms other potential circulating biomarkers in predicting survival in idiopathic pulmonary arterial hypertension. Heart 97 1054-1060.

40. Anand IS, Kempf T, Rector TS, Tapken H, Allhoff T, et al. (2010) Seria measurement of growth-differentiation factor-15 in heart failure: relation to disease severity and prognosis in the Valsartan Heart Failure Trial. Circulation 122: $1387-1395$

41. Kempf T, Björklund E, Olofsson S, Lindahl B, Allhoff T, et al. (2007) Growthdifferentiation factor-15 improves risk stratification in ST-segment elevation myocardial infarction. Eur Heart J 28: 2858-2865.

42. Kempf T, Sinning J, Quint A, Bickel C, Sinning C, et al. (2009) Growthdifferentiation factor-15 for risk stratification in patients with stable and unstable coronary heart disease: results from the AtheroGene study. Circ Cardiovasc Genet 2: 286-292.

43. Foley PW, Stegemann B, Ng K, Ramachandran S, Proudler A, et al. (2009) Growth differentiation factor-15 predicts mortality and morbidity after cardiac resynchronization therapy. Eur Heart J 30: 2749-2757.
44. Lindman BR, Breyley JG, Schilling JD, Vatterott AM, Zajarias A, et al. (2015) Prognostic utility of novel biomarkers of cardiovascular stress in patients with aortic stenosis undergoing valve replacement. Heart.

45. Bonaca MP, Morrow DA, Braunwald E, Cannon CP, Jiang S, et al. (2011) Growth differentiation factor-15 and risk of recurrent events in patients stabilized after acute coronary syndrome: observations from PROVE IT-TIMI 22. Arterioscler Thromb Vasc Biol 31: 203-210.

46. Velders MA, Wallentin L, Becker RC, van Boven AJ, Himmelmann A, et al (2015) Biomarkers for risk stratification of patients with ST-elevation myocardial infarction treated with primary percutaneous coronary intervention: Insights from the Platelet Inhibition and Patient Outcomes trial. Am Heart J 169: 879-889.

47. Wallentin L, Zethelius B, Berglund L, Eggers KM, Lind L, et al. (2013) GDF15 for prognostication of cardiovascular and cancer morbidity and mortality in men. PLoS One 8: e78797.

48. Wallentin L, Hijazi Z, Andersson U, Alexander JH, De Caterina R, et al 2014) Growth differentiation factor 15 , a marker of oxidative stress and inflammation, for risk assessment in patients with atrial fibrillation: insights from the Apixaban for Reduction in Stroke and Other Thromboembolic Events in Atrial Fibrillation (ARISTOTLE) trial. Circulation 130: 1847-1858.

49. Carstensen M, Herder C, Brunner EJ, Strassburger K, Tabak AG, et al. (2010) Macrophage inhibitory cytokine-1 is increased in individuals before type 2 diabetes diagnosis but is not an independent predictor of type 2 diabetes: the White hall II study. Eur J Endocrinol 162: 913-917.

50. Cavusoglu E, Marmur JD, Chhabra S, Hojjati MR, Yanamadala S, et al. (2015) Elevated baseline plasma phospholipid protein (PLTP) levels are an independent predictor of long-term all-cause mortality in patients with diabetes mellitus and known or suspected coronary artery disease. Atherosclerosis 239: 503-508.

51. Li H, Gao F, Xue Y, Qian Y (2014) [Value of plasma growth differentiation factor-15 in diagnosis and evaluation of type 2 diabetic nephropathy]. Nan Fang Yi Ke Da Xue Xue Bao 34: 387-390.

52. Lin JF, Wu S, Hsu SY, Yeh KH, Chou HH, et al. (2014) Growth-differentiation factor-15 and major cardiac events. Am J Med Sci 347: 305-311. 